\title{
FINITE ELEMENT SIMULATION OF A PASSIVE MAGNETIC ROBOTIC SYSTEM
}

\author{
Jinji Sun, ${ }^{* * *}$ Ziyan Ju, ${ }^{* *}$ and Hongliang Ren*
}

\begin{abstract}
To realize the stability of the passive magnetic robotic system, a novel combination of permanent magnets is proposed. As we know, a single passive magnetic levitation is impossible to suspend all degrees of freedom of a rigid body; this article researches the combination of multiple passive magnetic bearings by the finite element method (FEM) simulation. Through changing the magnetization direction of permanent magnets, the radial force and axial force can be changed correspondingly. Various magnetization angles of permanent magnets are analysed, and the relationships are analysed among radial force, axial force, and axial displacement. Finally, the optimized magnetization angle of the permanent magnets and their arrangements are proposed. According to the analytic results, it is feasible to realize the stability using the proposed configuration.
\end{abstract}

\section{Key Words}

Passive magnetic bearing, magnetization angle, arrangement, stable, simulation, magnetic materials and devices, FEM

\section{Introduction}

As we all know, application of the robotic system is increasing more and more widely nowadays [1], [2]. In order to improve its accuracy, variable suspension systems are used in the robotic system [3], especially the electromagnetic suspension system [4]. The types of magnetic bearings in the electromagnetic suspension system are active magnetic bearing (including hybrid magnetic bearing) and passive magnetic bearing (PMB). PMBs [5]-[7] have several advantages over active magnetic bearings $[8]-[10]$ because they require no input energy and no power consumption. So they have been used in the applications in flywheel [11], [12], control momentum gyro [13], high-speed motor [14], bearingless motor [15]-[17], and so on [18]. To the $\mathrm{PMB}$, the typical form is consisted of two monolithic permanent magnetic rings with either axial magnetization or

* Biomedical Engineering, National University of Singapore, 117575, Singapore; e-mail: sunjinji2001@163.com, ren@nus.edu.sg

** School of Instrumentation Science \& Opto-electronics Engineering, Science and Technology on Inertial Laboratory, Beihang University, Beijing 100191, China; e-mail: seujzy@163.com

Recommended by Dr. Peter Liu

(DOI: 10.2316/Journal.206.2017.1.206-4889) radial magnetization [19]. To realize higher displacement stiffness, layered PMB are widely used with Halbach magnetized array because it can use the arrangement of permanent magnets to increase the magnetic field on one side of the array while cancelling it on the other side [20]-[22]. The PMBs mentioned earlier can be adopted to provide force and few passive axial magnetic bearings are used to provide bigger gyro momentum in magnetically suspended control moment gyro (MSCMG) [23], [24]. More importantly, as stated in Earnshaw's theorem, passive magnetic levitation is impossible to suspend all degrees of freedom, so at least one degree of freedom (DOF) has to be active. Therefore, the magnetically suspended system mentioned earlier has one controlled DOF at least. Especially, a design for a PMB system that can stably levitate a rotor in all directions is described in the literature [25]. In the present system, the stability can only be realized in the lateral direction, but it still needs stabilization coils in the vertical direction whereas the permanent magnets with Halbach array can balance the gravity of the rotor.

In this article, the PMBs configuration is put forward. The relationship between axial force and axial displacement is analysed, as well as the radial force and radial displacement are measured. The various magnetization angles of permanent magnets are analysed by FEM in detail and the final magnetically suspended system is proposed with PMBs. Therefore, the proposed configuration can be realized stably when the movable part rotates.

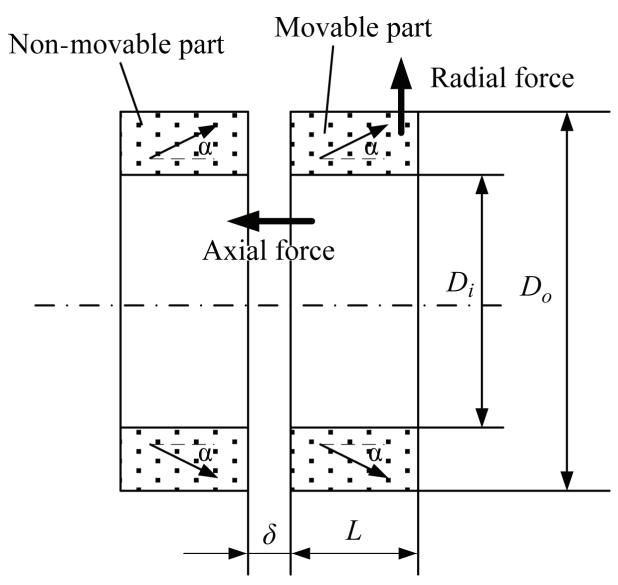

Figure 1. Structure of the PMB. 


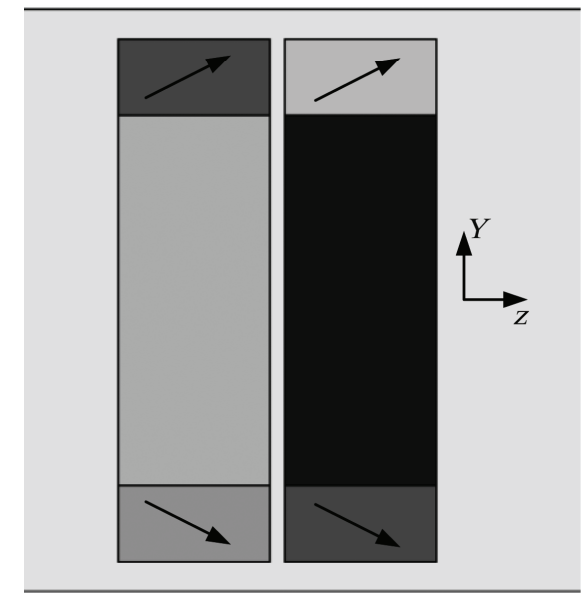

Figure 2. 2D FEM model of the PMB.

Table 1

Parameters of PMB

\begin{tabular}{|l|c|}
\hline Parameter & Value \\
\hline $\begin{array}{l}\text { Outer diameter of permanent magnet, } \\
D_{o} / \mathrm{mm}\end{array}$ & 35 \\
\hline $\begin{array}{l}\text { Inner diameter of permanent magnet, } \\
D_{i} / \mathrm{mm}\end{array}$ & 25 \\
\hline Length of permanent magnet, $L / \mathrm{mm}$ & 10 \\
\hline Length of air gap, $\delta / \mathrm{mm}$ & 1 \\
\hline $\begin{array}{l}\text { Remanence of permanent magnet, } \\
B_{r} / \mathrm{T}\end{array}$ & 1.2 \\
\hline $\begin{array}{l}\text { Coercive force of permanent magnet, } \\
H_{c} /(\mathrm{kA} / \mathrm{m})\end{array}$ & 796 \\
\hline
\end{tabular}

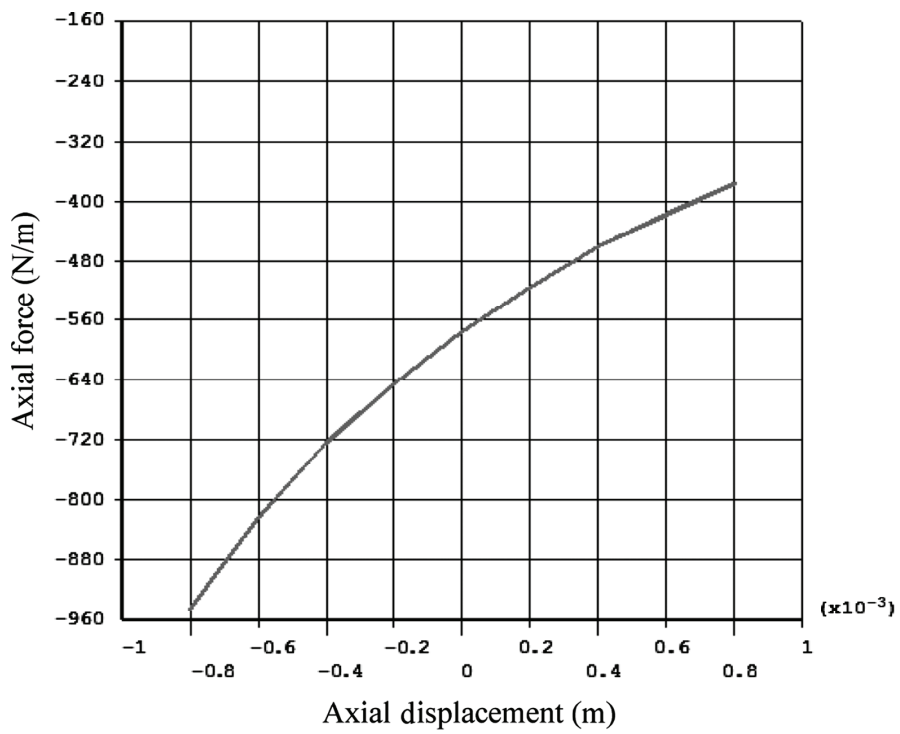

(a)

\section{Structure and Finite Element Analysis Simula- tion of Passive Magnetic Bearings}

The configuration and magnetization angle of the PMB are shown in Fig. 1. It consists of the non-movable part and movable part, which are made of permanent magnets.

In this figure, $D_{o}$ denotes the outer diameter of nonmovable part permanent magnet or movable part permanent magnet, $D_{i}$ denotes the inner diameter of non-movable part permanent magnet or movable part permanent magnet, $L$ denotes the length of non-movable part permanent magnet or movable part permanent magnet, $\alpha$ denotes the magnetization angle between non-movable part permanent magnet and movable part permanent magnet, and $\delta$ denotes the length of air gap between non-movable part permanent magnet and movable part permanent magnet.

The finite element 2D model is built by Ansys 14.0 for PMB as shown in Fig. 2. We can obviously see the permanent magnets and their magnetization direction. The parameters of the PMBs are illustrated in Table 1.

According to different magnetization angles of permanent magnets, the simulation results between forces and axial displacement are shown in Figs. 3 to 8 at $30^{\circ}, 40^{\circ}$, $45^{\circ}, 50^{\circ}, 60^{\circ}$, and $75^{\circ}$, respectively.

All the results are summarized as shown in Table 2. From this table, it can be seen that the PMB system can be made stable when the magnetization angles of permanent magnets are $45^{\circ}$ and $50^{\circ}$. The unit "m" means the length in the $x$ direction, and it refers to the length of half circumference (as shown in Fig. 2).

The reason is seen from Figs. 4 to 6 . From these figures, the axial force and radial force are all decreased when the axial displacement is increased. That is to say, the axial force and radial force will be large when the length of air gap $\delta$ is decreased, and the axial force and radial force will be small when the length of air gap $\delta$ is

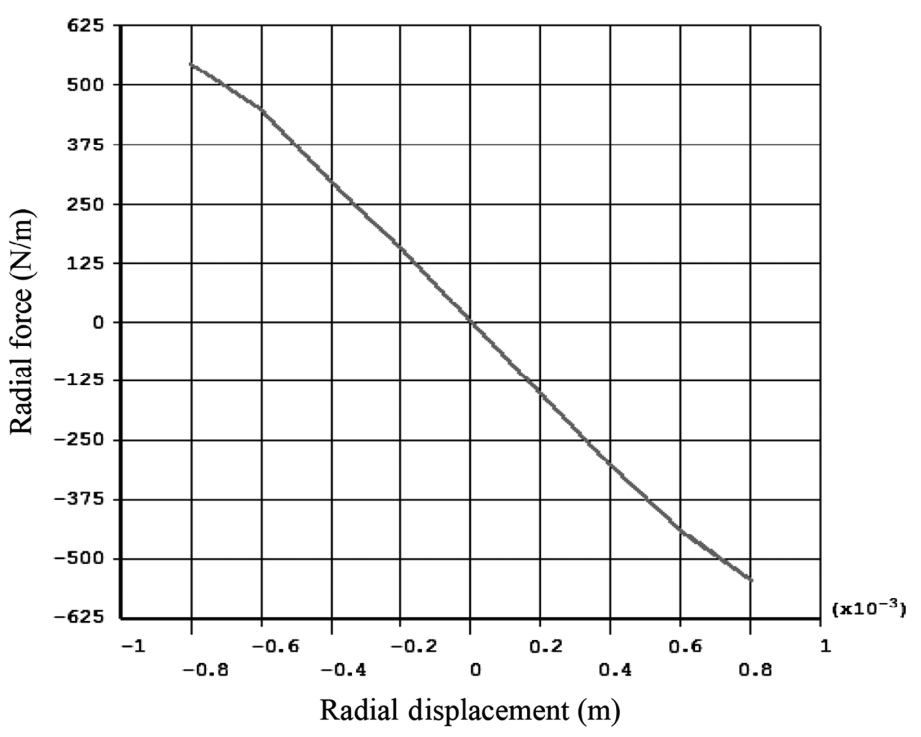

(b)

Figure 3. Relationships between forces and displacement at $\alpha=30^{\circ}$ : (a) axial force versus displacement and (b) radial force versus displacement. 


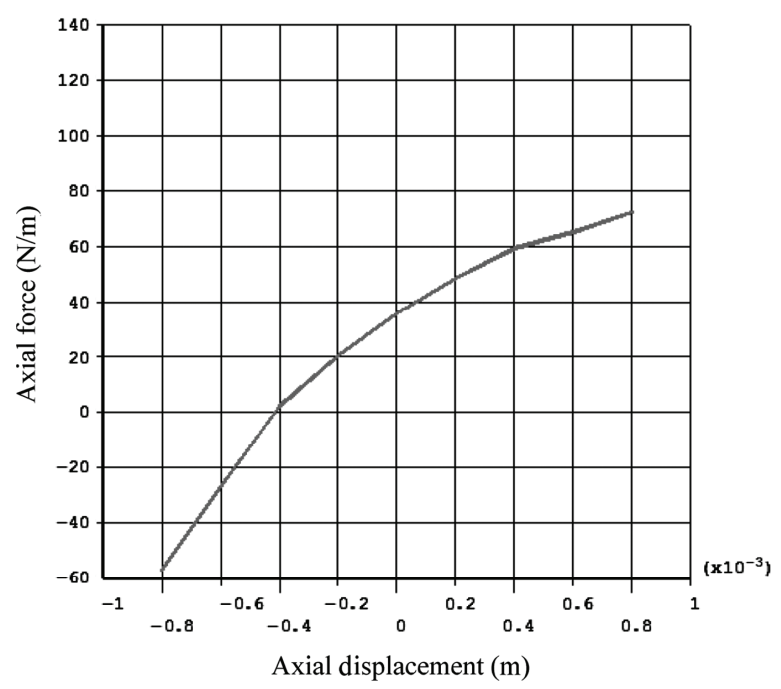

(a)

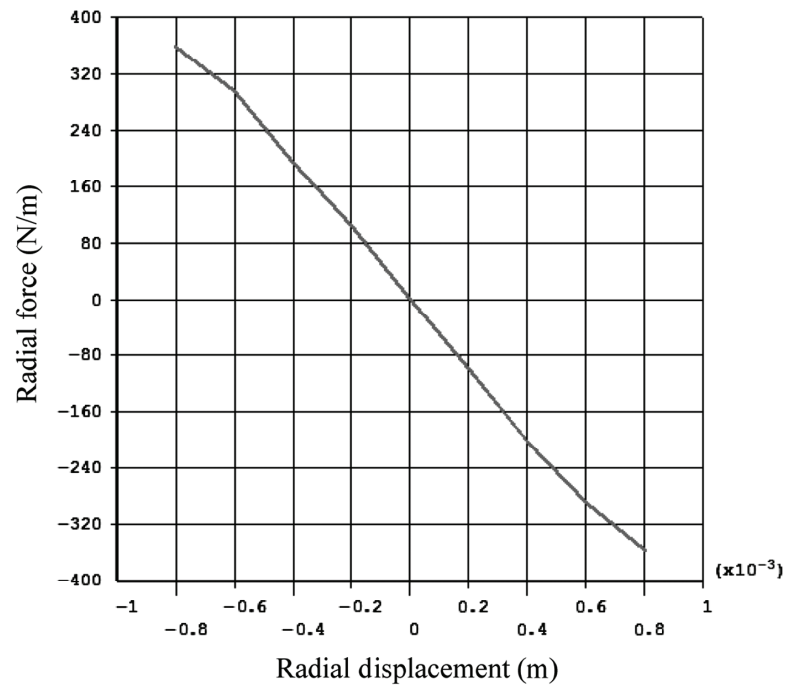

(b)

Figure 4. Relationships between forces and displacement at $\alpha=40^{\circ}$ : (a) axial force versus displacement and (b) radial force versus displacement.

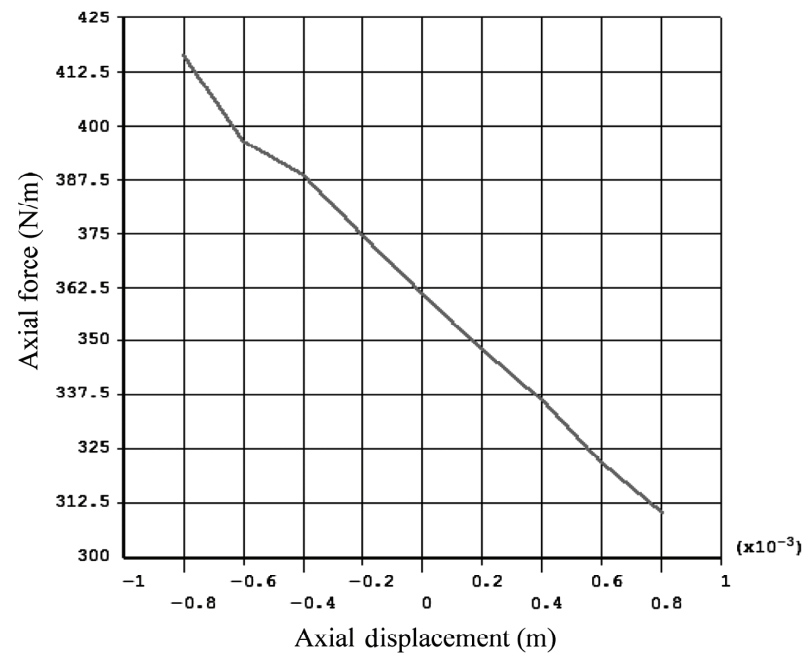

(a)

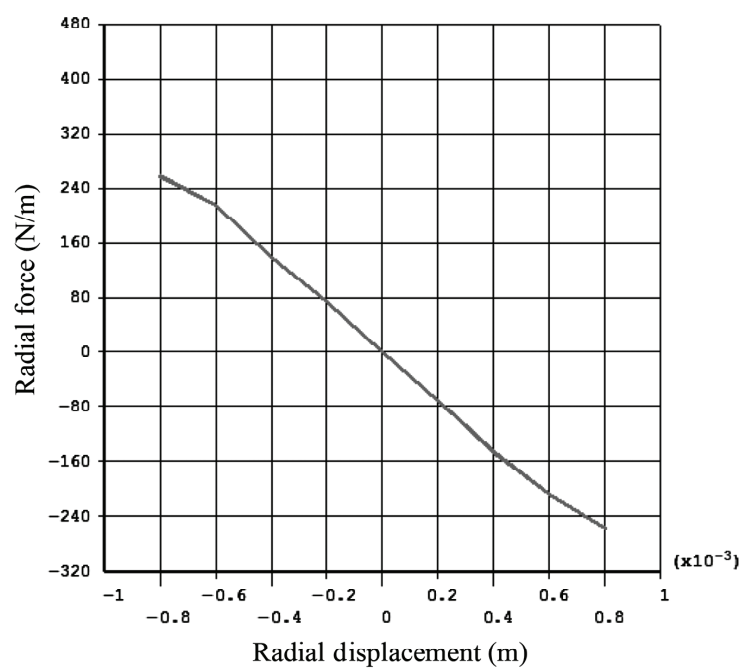

(b)

Figure 5. Relationships between forces and displacement at $\alpha=45^{\circ}$ : (a) axial force versus displacement and (b) radial force versus displacement.

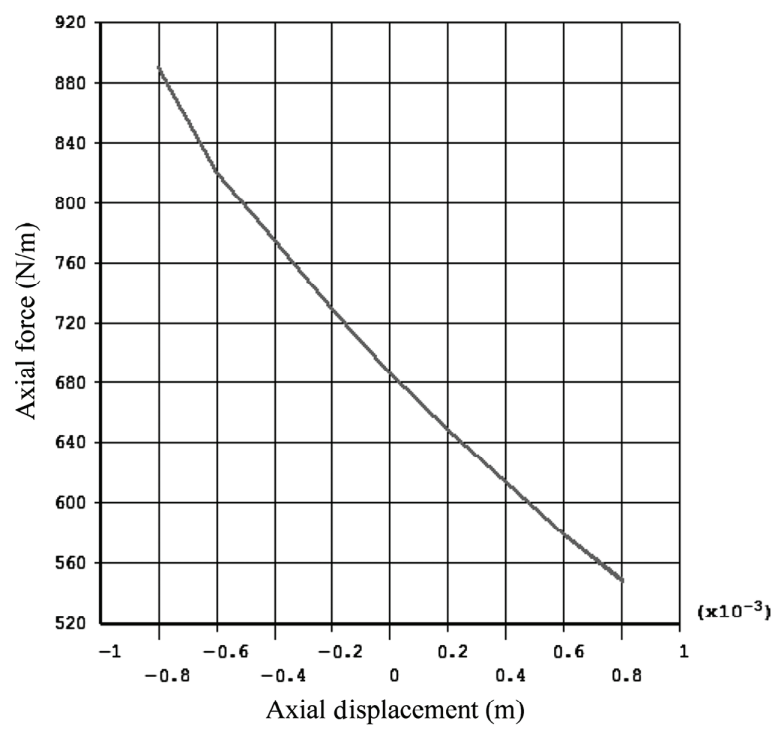

(a)

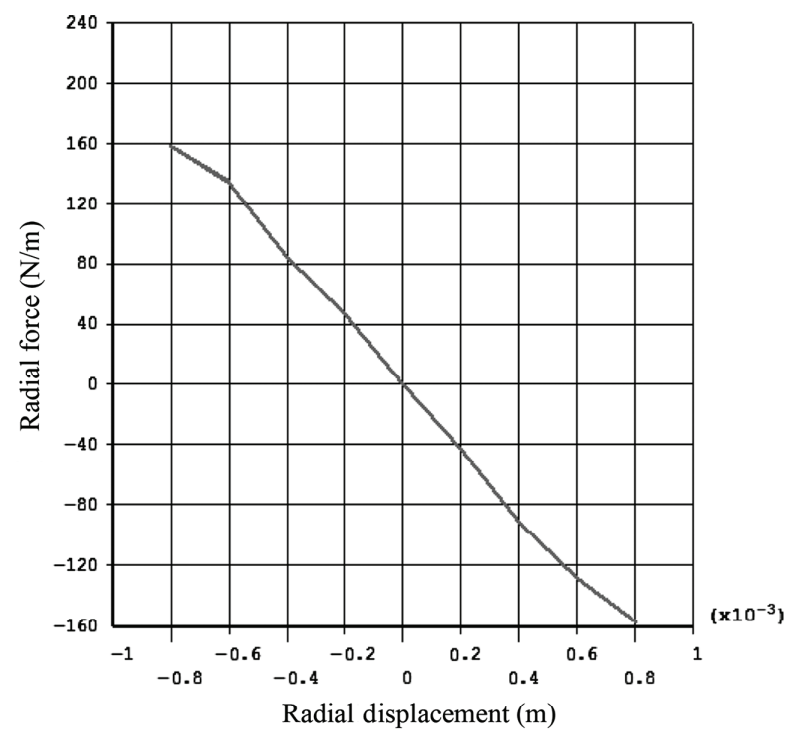

(b)

Figure 6. Relationships between forces and displacement at $\alpha=50^{\circ}$ : (a) axial force versus displacement and (b) radial force versus displacement. 


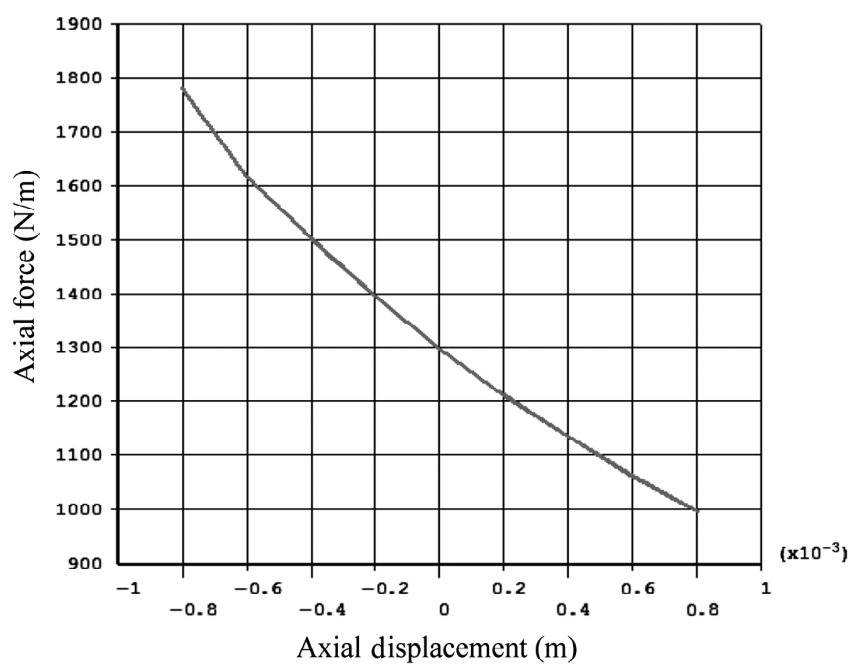

(a)

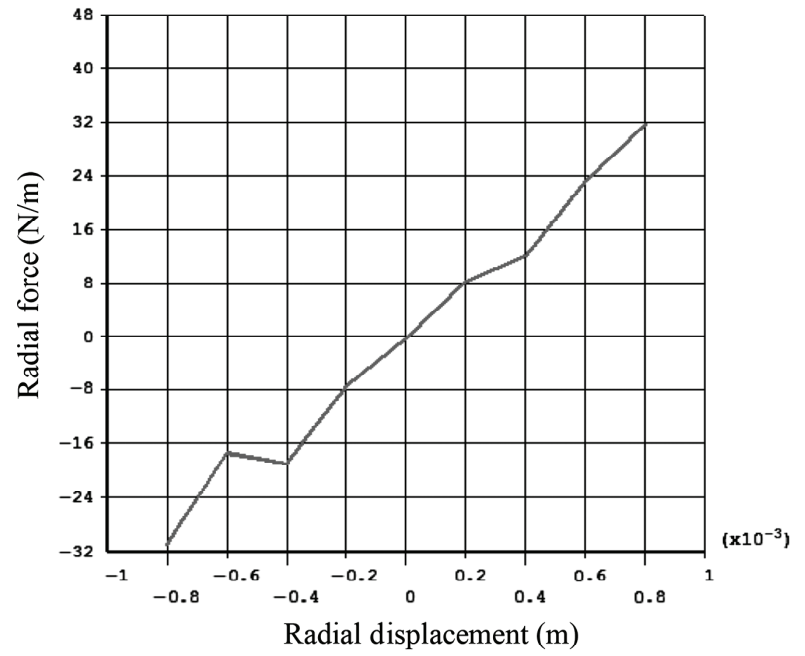

(b)

Figure 7. Relationships between forces and displacement at $\alpha=60^{\circ}$ : (a) axial force versus displacement and (b) radial force versus displacement.

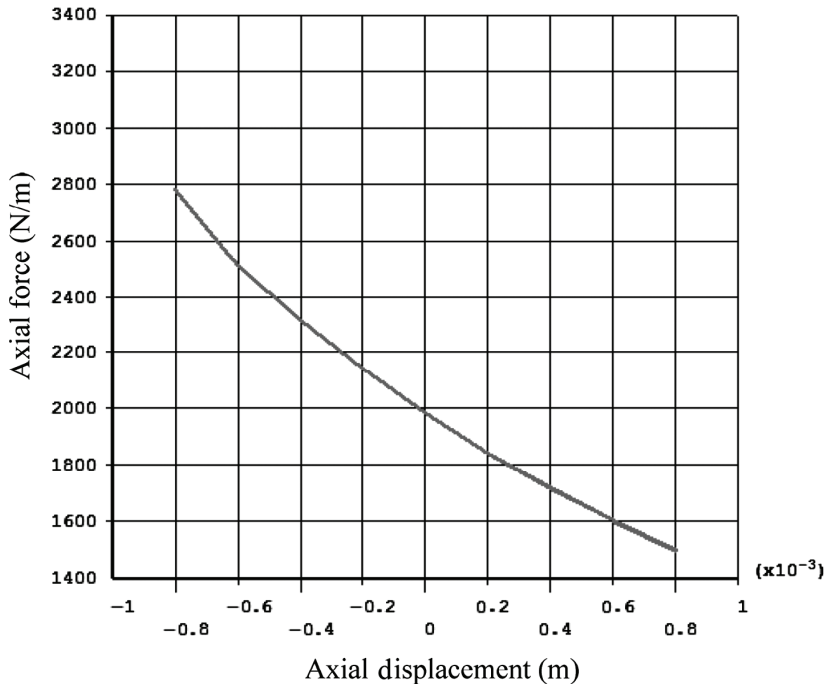

(a)

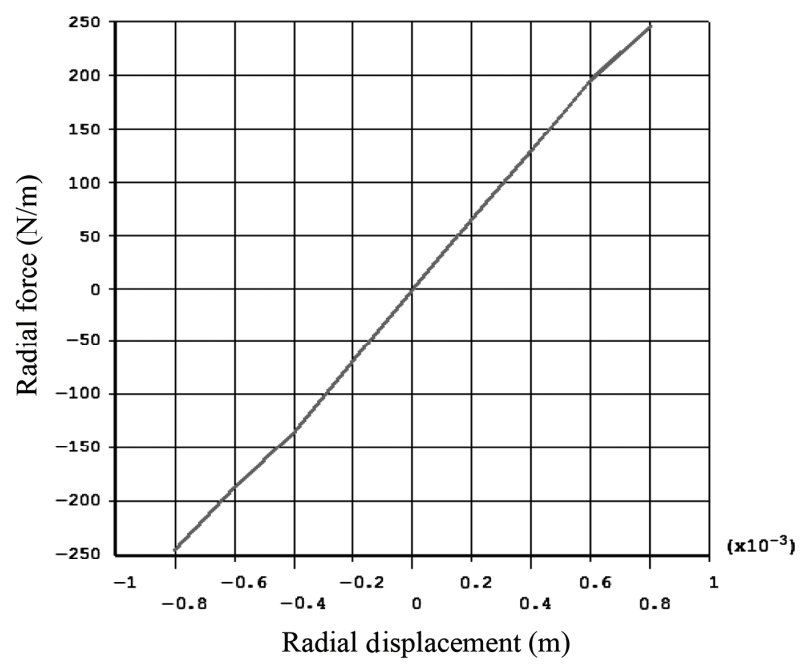

(b)

Figure 8. Relationships between forces and displacement at $\alpha=75^{\circ}$ : (a) axial force versus displacement and (b) radial force versus displacement.

Table 2

Analytic Results Summary of PMBs using FEM

\begin{tabular}{|l|c|c|c|}
\hline$\alpha$ & $\begin{array}{c}\text { Axial Stiffness } \\
(\mathrm{N} / \mathrm{m} / \mathrm{mm})\end{array}$ & $\begin{array}{c}\text { Radial Stiffness } \\
(\mathrm{N} / \mathrm{m} / \mathrm{mm})\end{array}$ & Effect \\
\hline $30^{\circ}$ & 356 & -650 & Axial unstable, radial stable \\
\hline $40^{\circ}$ & 81 & -437 & Axial unstable, radial stable \\
\hline $45^{\circ}$ & -66 & -312 & Axial stable, radial stable \\
\hline $50^{\circ}$ & -212 & -200 & Axial stable, radial stable \\
\hline $60^{\circ}$ & -500 & 40 & Axial stable, radial unstable \\
\hline $75^{\circ}$ & -812 & 312 & Axial stable, radial unstable \\
\hline
\end{tabular}




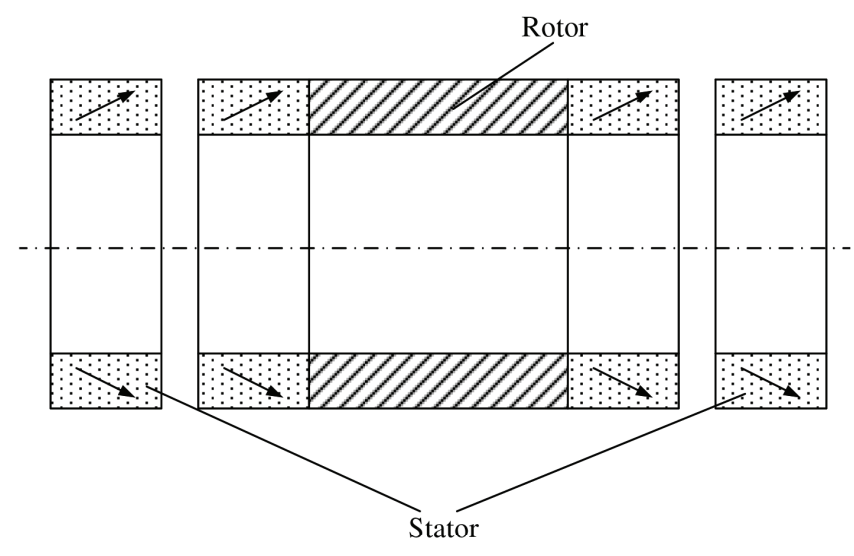

Figure 9. Stable magnetically suspended system with two pairs of PMBs.

increased. Therefore, when two pairs of PMBs are used, as shown in Fig. 9, the whole system can be realized as stable.

\section{Conclusion}

In this article, a magnetically suspended system with PMBs is proposed for stability, which is applicable for the robotic system. The magnetization angle of PMBs is analysed by FEM simulation in detail. The relationships among axial force, radial force, and axial displacement are analysed by using 2D FEM. The finite element analytic results show that the axial force changes from unstable to stable and the radial force changes from stable to unstable due to an increase in the magnetization angle. When the magnetization angles of permanent magnets are $45^{\circ}$ and $50^{\circ}$, the magnetically suspended system with two PMBs can be realized stable when the movable part rotates.

\section{Acknowledgement}

This work was supported by National Natural Science Foundation of China (Grant Nos. 51575025, 51405322), by the Foundation for the Author of National Excellent Doctoral Dissertations of China (Grant No. 201330), the Fundamental Research Funds for the Central Universities (Grant No. YWF-16-BJ-Y-23), and the Singapore Academic Research Fund (Grant No. R-397-000-173-133).

\section{References}

[1] S. Jiang, F. Sun, J.L. Lou et al., Kinematics, error analysis, and compensation of a high precision tendon-based MRI-compatible robot, International Journal of Robotics 83 Automation, 30(4), 2015, 333-344.

[2] F.Y. Xu, J.L. Hu, X.S. Wang et al., Helix cable-detecting robot for cable-stayed bridge: Design and analysis, International Journal of Robotics \& Automation, 29(4), 2014, 406-414.

[3] K. Alipour, S.A.A. Moosavian, and Y. Bahramzadeh, Dynamics of wheeled mobile robots with flexible suspension: Analytical modeling and verification, International Journal of Robotics ES Automation, 23(4), 2008, 242-250.

[4] A. Suebsomran, Adaptive neural network control of electromagnetic suspension system, International Journal of Robotics E Automation, 29(2), 2014, 144-154.

[5] T. Azukizawa, S. Yamamoto, and N. Matsuo, Feasibility study of a passive magnetic bearing using the ring shaped permanent magnets, IEEE Transactions on Magnetics, 44(11), 2008 , $4277-4280$

[6] T. Ohji, S. Ichiyama, K. Amei et al., A new conveyor system based on a passive magnetic levitation unit having repulsivetype magnetic bearings, Journal of Magnetism and Magnetic Materials, 272, 2004, e1731-e1733.

[7] J.M.D. Coey, Permanent magnet applications, Journal of Magnetism and Magnetic Materials, 248(3) 2002, 441-456.

[8] M.G. Farmakopoulos, P.G. Nikolakopoulos, and C.A. Papadopoulos, Design of an active hydromagnetic journal bearing, Proceedings of the Institution of Mechanical Engineers Part J - Journal of Engineering Tribology, 227(7), 2013, 673-694.

[9] H. Wang, K. Liu, and P. Ao, Magnetic field and specific axial load capacity of hybrid magnetic bearing, IEEE Transactions on Magnetics, 49(8), 2013, 4911-4917.

[10] J.C. Fang, C.E. Wang, and T. Wen, Design and optimization of a radial hybrid magnetic bearing with separate poles for magnetically suspended inertially stabilized platform, IEEE Transactions on Magnetics, 50(5), 2014, 8101011.

[11] M. Subkhan and M. Komori, New concept for flywheel energy storage system using SMB and PMB, IEEE Transactions on Applied Superconductivity, 21(3), 2011, 1485-1488.

[12] B.C. Han, S.Q. Zheng, X. Wang et al., Integral design and analysis of passive magnetic bearing and active radial magnetic bearing for Agile satellite application, IEEE Transactions on Magnetics, 48(6), 2012, 1959-1966.

[13] J.J. Sun, D. Chen, and H.L. Ren, Modeling and control of an integrated axial passive and radial active magnetic bearing system, IEEE International Conference on Information and Automation (ICIA), Yinchuan China, 2013, 682-687.

[14] J.C. Fang, Y. Le, J.J. Sun et al., Analysis and design of passive magnetic bearing and damping system for high-speed compressor, IEEE Transactions on Magnetics, 48(9), 2012, 2528-2537.

[15] J. Asama, T. Asami, T. Imakawa et al., Effects of permanentmagnet passive magnetic bearing on a two-axis actively regulated low-speed bearingless motor, IEEE Transactions on Energy Conservation, 26, 2011, 46-54.

[16] E. Severson, A. Rokke, R. Nilssen et al., Design and measurement of a passive thrust magnetic bearing for a bearingless motor, IEEE Industrial Electronics Society, IECON 2013 - 39th Annual Conference, Austria Center Vienna Vienna, Austria, 2013, 2720-2725.

[17] J. Asama, D. Watanabe, T. Oiwa et al., Development of a one-axis actively regulated bearingless motor with a repulsive type passive magnetic bearing, International Power Electronics Conference (IPEC-Hiroshima 2014 - ECCE-ASIA), 2014, 988-993.

[18] I. Joe, Development and testing of a passive magnetic support and damping (PMSD) system, Ninth International Symposium on Magnetic Bearings, Lexington, KY, 3-6 August 2004.

[19] B.C. Han, S.Q. Zheng, Y. Le et al., Modeling and analysis of coupling performance between passive magnetic bearing and hybrid magnetic radial bearing for magnetically suspended flywheel, IEEE Transactions on Magnetics, 49(10), 2013, 5356-5370.

[20] F. Xu, T. Li, and Y. Liu, A study on passive magnetic bearing with Halbach magnetized array, International Conference on Electrical Machines and Systems, Wuhan China, 2008, 417420.

[21] E. Marth, G. Jungmayr, and W. Amrhein, A 2D-based analytical method for calculating permanent magnetic ring bearings with arbitrary magnetization and its application to optimal bearing design, IEEE Transactions on Magnetics, 50(5), 2014, 7400308.

[22] J. Iniguez and V. Raposo, Numerical simulation of a simple lowspeed model for an electrodynamic levitation system based on a Halbach magnet array, Journal of Magnetism and Magnetic Materials, 322(9), 2010, 1673-1676.

[23] G. Carron de la Morinais, C. Salenc, M. Privat et al., Mini CMG Development for Furture European Agile Satellite, Proceedings of the 5th International ESA Conference on Spacecraft Guidance, Navigation and Control Systems, Frascati, Italy, 2003, 105-108. 
[24] J.J. Sun, Y. Ren, and J.C. Fang, Passive axial magnetic bearing with Halbach magnetized array in magnetically suspended control moment gyro application, Journal of Magnetism and Magnetic Materials, 323(15), 2011, 2103-2107.

[25] K.D. Bachovchin, J.F. Hoburg, and R.F. Post, Stable levitation of a passive magnetic bearing, IEEE Transactions on Magnetics, 49(1), 2013, 609-617.

\section{Biographies}

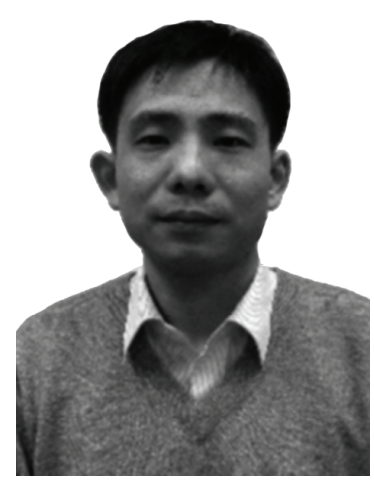

Jinji Sun received the Ph.D. degree in instrument science and technology from Beihang University, Beijing, China in 2010. Also, he is currently a Research Member at Key National Defense Lab of Novel Inertial Instrument and Navigation System Technology, School of Instrumentation Science \& Opto-electronics Engineering, Beihang University, Beijing, China. His research interests include the design of various novel types of magnetic bearings and brushless DC motors.

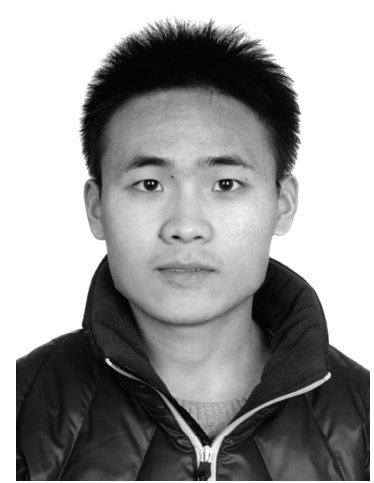

Ziyan Ju was born in Hebei, China in December 1992. He received the B.Eng. degree in Measurement and Control Technology and Instruments in 2015 from southeast university, Jiangsu, China. He is working towards M.Eng. degree at Beihang University, Beijing, China. His current research interests are control of magnetic bearing, electromagnetic design, and test of magnetic

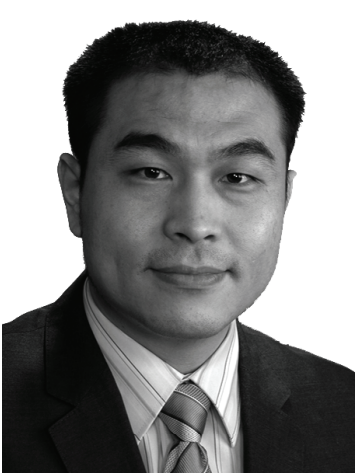

Hongliang Ren is currently an assistant professor and leading a research group on medical mechatronics in the Biomedical Engineering Department of National University of Singapore (NUS). $\mathrm{He}$ is an affiliated Principal Investigator for the Singapore Institute of Neurotechnology (SINAPSE) and Advanced Robotics Center at National University of Singapore. Dr. Ren received his Ph.D. in Electronic Engineering (specialized in Biomedical Engineering) from The Chinese University of Hong Kong (CUHK) in 2008. After his graduation, he worked as a Research Fellow in The Johns Hopkins University, Children's Hospital Boston \& Harvard Medical School, and Children's National Medical Center, USA. His main areas of interests include biomedical mechatronics, magnetic actuation and sensing in medicine, computer-integrated surgery, and robotics in medicine.

bearing's stiffness. 